\title{
Transparency and communication can improve wildlife welfare outcomes: A case of kangaroos
}

\author{
Peter Simmons, ${ }^{1, *}$ \\ ${ }^{1}$ School of Communication and Creative Industries, Institute for Land, Water and Society, Charles \\ Sturt University, Bathurst, Australia. The author is a member of the Bathurst Kangaroo Project.
}

\begin{abstract}
All countries manage human and wildlife coexistence. Where traditionally humans may have killed animals perceived to be a problem, this is often no longer legal or socially acceptable. Decision-makers tend to feel less strongly about coexistence issues than the people who attempt to influence them on behalf of human or wildlife interests. It has been argued that links between human interests and decisions affecting wildlife should be transparent, and that open decision making processes involving a range of local stakeholders will improve outcomes for humans and wildlife. This paper examines one case incident in an ongoing conflict between an international car racing track and kangaroos that have occasionally been found on the track during a race, causing danger to themselves and race participants. A secret local government report and plan to cull kangaroos was obtained using Freedom of Information legislation. When released to the media the subsequent public discussion showed a much greater concern for kangaroo stress, harm and right to live than the official report, and called for consideration of a range of alternatives to culling. This led to postponement of culling plans, and commitment to a more open community discussion of options. The case clearly supports claims that greater transparency and local stakeholder participation in management decision processes can improve welfare outcomes for non-human animals.
\end{abstract}

\section{Introduction - culling kangaroos, a contentious issue}

The kangaroo is one of the world's iconic non-human animals alongside lions, elephants and tigers. Yet at home in Australia discourses concerning kangaroos vary between reverence for a national symbol on crests and currency, and contempt as a pest to be eradicated. Decisions about whether or not to cull kangaroos are ongoing and highly contentious. It has been argued that officials who work for authorities and make decisions affecting wildlife often feel less strongly about issues of coexistence than people who lobby or otherwise attempt to influence them on behalf of wildlife or human interests [1,2]. Communicators have an important role to play in the wellbeing of non-human animals because they can explore and influence attitudes and understanding of publics, stakeholders, and the humans who make important decisions affecting kangaroos. Recent research has called for greater transparency in decision processes affecting wildlife, as a way to improve outcomes for kangaroos as well as humans [3-5].

\footnotetext{
*Corresponding author: psimmons@csu.edu.au
} 
In every country humans make decisions about how to coexist with non-human animals. This paper presents a recent incident in the case of a long-running conflict between lucrative high technology human recreation in the form of a motor race, and an ancient species, the kangaroo. The paper daws on recent research into human-wildlife coexistence to analyse a confidential document recommending kangaroo culling obtained under Freedom of Information legislation in March 2016, and newspaper accounts which appeared in subsequent days and weeks. Irrespective of the rights and wrongs of the claims of different human parties involved, the case illustrates the negative consequences that can arise for wildlife when decisions affecting non-human animals are made without transparency and accountability to a range of stakeholders.

The paper provides a background to kangaroos and the issue of culling, and communication and decisions affecting wildlife. It then presents the case, illustrating key themes concerning the importance of communication and transparency, followed by a discussion of insights from this case.

\section{Culling, justifications and calls for more transparency}

Kangaroos are a protected species in Australia and it is necessary to obtain a licence to kill them. Recent research has called for increased transparency in processes and enhanced accountability in justification for killing kangaroos. Licenced killing of kangaroos is the world's largest commercial kill of wild animals on land. Each year licences are approved to kill more than 1 million [6]. They are mostly killed for their meat and fur [3]. The annual value to Australia has recently been estimated at $\$ 88.8$ million AUD (\$63.1 USD), and 880 full time equivalent jobs [3]. Although a small part of Australia's agricultural economy, the jobs are significant to those workers and their families. When communicating about culling the kangaroo industry tend to emphasise themes of pest control, harvesting an abundant resource, and adherence to a strict national code concerning the requirement to kill instantly with a single shot to the head with approved firearms [7]. Critics of culling processes have stressed cruelty [4] and the lack of enforcement and compliance with the provisions of the code in the remote sites where killing tends to take place [6]. Some have also questioned the science and other claims used to justify killing, such as over abundance and damage to environments. In a recent newspaper story about culling kangaroos, Dr Daniel Ramp suggested confusion between attitudes to culling and land use:

"The problem with this notion of over abundance is that it often gets muddied with attitudes of land use...In actual fact from purely an ecosystem point-of-view, I have never seen a situation where kangaroos on their own without anything else happening are causing problems where they're out of balance or their not being driven by anything else in the environment. It just doesn't happen." [8].

To improve kangaroo welfare Boom et al (2013) called for a range of improvements in processes including improved training in humane killing, increased penalties for violations, and more effective screening and scrutiny in the granting of culling licences [6]. Officials who make important decisions concerning the coexistence of humans and wildlife often find themselves between interest groups with polarised views, and in situations where some people are bound not to be pleased, whatever the decision [5]. According to BoronyakVasco \& Perry [3], economic arguments tend to dominate policy decisions affecting kangaroos, thus favouring industry interests, while 'animal protection advocates represent a group of stakeholders who have legitimate concerns over the commercial kangaroo industry', but 'currently have no economic mechanism to voice their interests' [3]. Researchers have reported that the values of the wider public and government agencies responsible for wildlife management are frequently quite different [9] and that the views of 
large numbers of people are either ignored or not heard [10], raising the possibility that large numbers of animals are killed or otherwise harmed in ways that would not be approved by the citizens that decision-makers are representing. Studies in Canada reported that the public and experts agreed on potential harm levels, but management strategies that involved killing animals often lacked broad public support [11].

An online study of the reasons people give for their attitudes to culling kangaroos found that attitudes to culling were nuanced, complex and often contradictory, even within individuals [5]. There were small minorities who held extreme attitudes either for, such as killing for enjoyment or against culling under any ciorumstance. More commonly, attitudes were conditional. Some accepted culling when the meat or fur was not wasted, others said culling was unacceptable for economic gain or human convenience, and would only kill if the individual kangaroo or mob were in danger from disease or starvation. Importantly, they reported that attitudes often conflated with other interests such as cost, inconvenience or perceived attitides of family and social groups.

'An urban-rural divide promulgated by some culling proponents may fuse cultural/political allegiances with attitudes to culling in ways that undermine kangaroo welfare. Humans charged with wildlife management and decision-making should aim to make assessments that benefit wildlife as well as humans' [5].

The researchers called for research into the circumstances influencing acceptance of different approaches to wildlife management. They also called for research into identifying and making relationships between human interests and decisions affecting animal welfare more transparent [5]. Ramp (2016) also called for greater transparency, arguing that many decisions are made without consultation or understanding of the priorities and preferences of the wider publics represented by decision-makers [8]:

'We live in a democracy and we should always have open discourse about the decisions we take, particularly when they include killing animals. Governments really should be open to listening to good management and good science, and also different attitudes within the community. I think you would find that most people don't feel comfortable about the killing of kangaroos. And governments should be listening to that and finding alternate ways to share space.' [8]

Authorities in democratic and even many non-democratic countries are under increasing pressure to listen to stakeholders and enable them to participate in decision-making. Calls for transparency in treatment of animals used in research have led to a range of written commitments and agreements and ongoing work towards alignment of industry practices and public expectations of openness about suffering, procedures used to enhance animal welfare, and possible alternatives $[12,25]$. In the case of wildlife, traditional responses to kill problem wildlife are no longer legal or socially acceptable [13] and killing today should be treated as a last resort [10]. Decisions need to be carefully justified, and familiarity with stakeholder and public beliefs about wildlife management aids good communication [14]). Environmental researchers have argued that communicators and social scientists have an important role to play in understanding attitudes to human and wildlife interaction $[15,13]$. Better understanding of perspectives and options [2] and involvement of a range of local stakeholders in decision processes [13] can improve outcomes for humans and wildlife.

This section overviewed the culling of kangaroos and perspectives of proponents and opponents. It has also suggested that economic arguments tend to dominate policies affecting kangaroos, that attitudes to culling often conflate with social and economic interests, that culling is today more likely to be popularly regarded as a last option, and that kangaroo welfare may be improved with more transparency concerning the relationship 
between human interests and decisions to cull. The next section presents the case of a proposal to cull kangaroos to improve the safety of motor racing drivers.

\section{Culling kangaroos for a car race}

\subsection{Background - 2009 cull leads to community complaints}

Bathurst in NSW Australia is the home of an internationally renowned motor car race. The circuit on Wahluu/Mt Panorama is 6.2 kilometres, and just 3 kilometres from the city centre. Total attendance over 4 days at the main annual race event in 2012 was 207,205, bringing \$25.28 million and the equivalent of 255 jobs into Bathurst [16]. Car racing thus brings significant income to the city and region.

The winding track is usually a public road with a $60 \mathrm{kmh}$ speed limit. During races cars average around $170 \mathrm{kmh}$ on the circuit and achieve top speeds of nearly $300 \mathrm{kmh}$. At each meet there are several classes of vehicles racing over several days, with many millions of kilometres covered over the years.

Wahluu/Mt Panorama is also home to several families of mostly eastern grey kangaroos, totalling about 1000 . Occasionally kangaroos get onto the circuit during a race. Around roads Kangaroos are unpredictable and dangerous to themselves and motorists at even the best of times. During a high speed race they are potentially lethal. Since 2004 there have been 9 incidents involving kangaroos on the track, 5 where a car collided with a kangaroo. No humans have been injured in these incidents involving kangaroos [17].

In 2009 the public found out through the media that Bathurst Regional Council (BRC) had secretly killed 140 eastern grey kangaroos on Mount Panorama [18]. The media reported that the decision had been approved by senior council management and correctly licenced, although it emerged that the full committee of elected councillors had not been consulted about the decision to cull:

'I'm in a very difficult position as a councillor because council staff took it on board as an internal management issue and didn't make the councillors privy to their decision to cull the kangaroos. And I'm very concerned for the huge outcry there has been for the killing of the kangaroos and I can't account for how it was done, where it was done, whether it was necessary, because I haven't been privy to the information ... I think it would have been very different had there been a consultation with both the elected representatives and the fauna management people in the region of how to deal with this issue. So I think it's been a bit of a disaster for the council... From the advice I've had from the fauna experts it [culling] is kind of the last tool that they resort to. There are other measures that they would try to introduce to manage kangaroos, other than a direct cull.' [19].

Once word got out to the public, the council received considerable negative feedback locally, nationally and internationally about the culling, through various media, and also from direct public complaints. In following years the issue has continued to surface periodically, and has attracted media attention globally. The Bathurst motor-race circuit / kangaroo conflict features on news pages in many countries including leading media sites such as the BBC [20] and in several languages. The race is televised internationally and earns considerable broadcast revenue, and links between the race and killing kangaroos are undesirable for commercial interests. The 2009 cull and subsequent threats to cull kangaroos led to some organised local movements to find alternative solutions. In 2014 the Bathurst Kangaroo Project (BKP) was formed as 'a collaborative science \& research project supporting informed solutions for coexistence between kangaroos \& community' 
[21]. This community-led initiative attracted the interest of conservation biologists at the University of Technology in Sydney and led to a series of studies of the Wahluu/Mount Panorama kangaroos and their habitat. The Bathurst Regional Council contributed funds and other resources to support several research projects.

\subsection{The 'secret plan for a cull' in 2016}

On 31 March 2016 Bathurst's newspaper the Western Advocate ran a story headed 'Bathurst Regional Council's secret plan for a cull on the Mount', see Figure 1 [22]. Using Freedom of Information (FOI) laws the Australian Society for Kangaroos (ASK) had obtained and passed onto the media a BRC report from December 2015 revealing plans for a cull of kangaroos after the 2016 Easter races. A report marked 'CONFIDENTIAL' from the Director Corporate Services \& Finances recommended application to cull kangaroos posing '.. a serious threat to motorsport participants competing at Mount Panorama during scheduled motor racing meetings' [17]. It listed 9 incidents involving kangaroos since 2004. 'Luckily to date these encroachments have only resulted in vehicular damage and no injury to persons' [17]. The report did not mention harm to kangaroos.

The report says the population of kangaroos appears stable, and that there is increasing race activity each year, particularly prior to sunrise when kangaroos are most active. The report does not discuss the possibility of racing at other times when kangaroos are less active. The report refers to research conducted by UTS, and improved understanding of kangaroo movements and habits. 'To date no real solution has been presented' [17].

'Given the high potential for conflict between kangaroos and Motorsport events, the time is now opportune to create an impact on kangaroo numbers in the Mount Panorama precinct by way of a further cull' [17].

The report then says that relocation of the kangaroos is not viable, and that current fencing is 'not providing a sufficient deterrent' [17] to kangaroos getting on the track during racing. A memorandum from the Director of Corp Services and Finance on 10/12/015 to the Director of Engineering Services, also obtained under FOI, notes that council has resolved to approve application for a cull of kangaroos. Another memorandum to elected councillors on 14/12/2015 and signed by the General Manager says that no application will be made until after the Easter car race event, and that before an application is made 'a report will come back to Council in open session' [17].
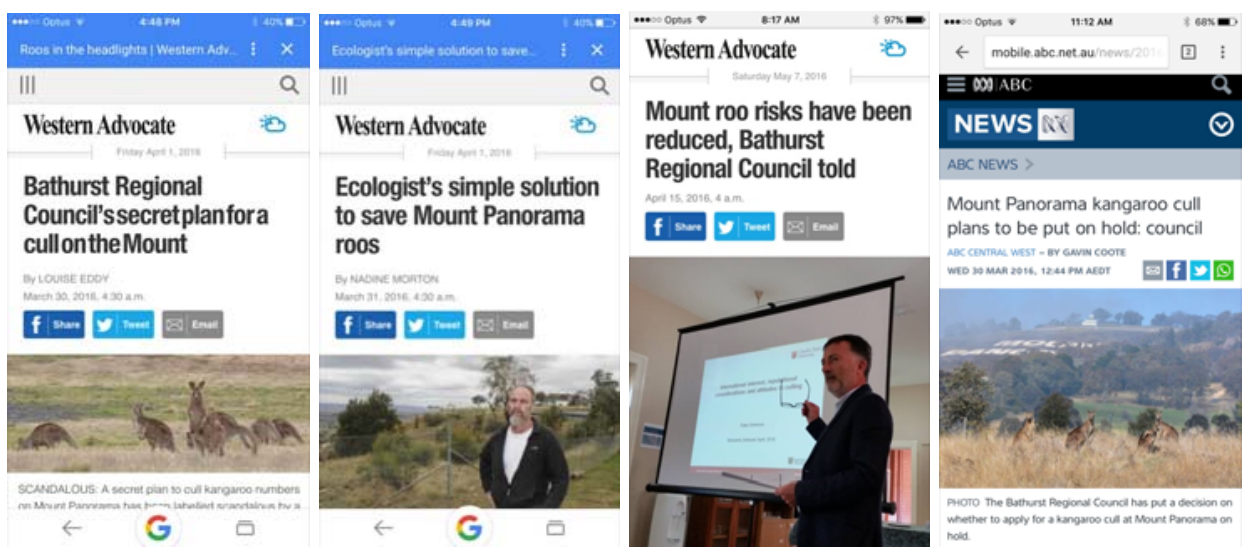

Figures 1, 2, 3, 4. Plans to cull changed quickly once stakeholders were aware and involved 
In days following the story of the planned cull another media story appeared: 'Ecologist's simple solution to save Mount Panorama Roos', see Figure 2 [23]. A local Ecologist with a long experience of kangaroos on Wahluu/Mount Panorama was reported saying that the problem could be fixed by using knowledge of kangaroo movements to install appropriate fencing.

'It's not a numbers thing, it's an attitude thing ... there's just a mindset that culls have to happen' [23]

A founder of the Bathurst Kangaroo Project was also quoted saying that council needed to take advice from experts, and fix holes in fences and their 'track clearance protocols' [23]. A community-led 'roundtable' was organised where local wildlife experts and landholders, and biologists, ecologists and social scientists from three universities, suggested alternative perspectives and approaches to managing coexistence of kangaroos and car racing.

When the story of a 'secret plan for a cull' broke in the media the council were quick to downplay the inevitability of a cull [Figure 4]. The mayor was quoted in interviews across media [see Figure 3] saying that following recent race events held without kangaroo incident there was optimism that fencing and other strategies were working [24]. Further, that no decision about a cull would be taken until after 'effectiveness of current coexistence programs could be measured' and an 'all-embracing discussion' [24].

The president of the Australian Society of Kangaroos, the organisation that obtained the report and made the process more transparent by sharing it with the media and other stakeholders was also quoted. She expressed concern that a cull had been considered at all by the Council, but that it was '... good that they're taking on board our concerns and concerns of the public ...' [24].

\section{Conclusions}

The important insight we glean from this case is that the welfare prospects of animals, who cannot ever speak for themselves, were clearly enhanced when a closed local authority decision process was opened to a wider group of stakeholders. In this instance, deliberations over the wildlife management strategy were made transparent only when the authority was required by Freedom of Information request. It may transpire that a future, open and 'all-embracing discussion' [24] process in the community results in a decision to cull Wahluu/Mount Panorama kangaroos, to make racing safer for drivers who visit several times a year. At the very least, the kangaroos around Wahluu/Mount Panorama that would have been culled, and their families, have received a stay of execution.

The case supports recent suggestions from Ramp [8], Mehmet and Simmons [5] and Bergstrom et al [10] that a lack of transparency in coexistence decisions can lead to adverse outcomes for wildlife welfare. Behind the scenes the official correspondence emphasised human concerns for recreation safety and economic interests [3], and was dismissive of alternative solutions to culling, when compared to the subsequent public discourse in the media. The inclusion of media and other stakeholders - local ecology and fauna experts, community and animal protection groups - led to much greater recognition of the welfare interests of the kangaroos including stress, injury and their rights to live around Wahluu/ Mount Panorama. A broader set of non-lethal options for problem-solving were canvassed than the traditional cull. The case suggests support for Treves et al's assertion that incorporation of local stakeholders as partners in planning and management can improve outcome for wildlife as well as humans [13], and the claim that publics are often more likely than authorities to prefer non-lethal solutions in wildlife management [11].

'Transparency involves communicating meaningful information (eg, data or details of decision-making processes) to audiences, openly and honestly, with the intention of informing, enabling understanding and meeting responsibilities of accountability' [25]. 
Studies in the UK indicate popular support for transparency about how non-human animals used in research are used, how many suffer and how much, care shown for welfare, and whether alternatives to suffering have been considered [12]. There is increasing evidence of popular support for similar transparency and accountability concerning the treatment and welfare of non-human animals in the wild. Decision processes will need to include meaningful participation by community members [11] and communicators may play increasingly important roles in ensuring the feasibility and quality of such processes.

The authority to make life and death decisions comes with great responsibility. Increasingly that responsibility includes meeting community expectations of transparency and sensitivity to the needs of non-human animals. This paper supports and recommends further research into processes where humans manage life, death and welfare for nonhuman animals. Non-human animals will benefit when processes involve participation of, and accountability to, a wide range of stakeholders.

1. E. S. Paul. Society \& Animals, 3(1), 1-21 (1995)

2. S. Dubois, H.W. Human Dimensions of Wildlife, 18(1), 1-19 (2013)

3. L. Boronyak-Vasco, N. Perry. Ecological Economics, 114, 159-167 (2015)

4. D. Ramp. Journal of bioethical inquiry, 10(2), 267-272 (2013)

5. M.Mehmet, P. Simmons. Environmental Communication (to be published)

6. K. Boom, D. Ben-Ami, L. Boronyak and S. Riley. International Journal of Rural Law and Policy, 2 (2013).

7. J. Kelly. Kangaroo Industry Background. Kangaroo Industry Association of Australia (KIAA) (2013) . Retrieved 23 April 2016 from http://www.kangaroo-industry.asn.au/morinfo/kangaroo_industry_background.pdf

8. D. Ramp in J. Hall. Doubts over kangaroo culling science. The Age newspaper, 23 April, 2013. Retrieved online on 24 April, 2016 from http://www.theage.com.au/actnews/doubts-over-kangaroo-culling-science-20160408-go1u5k

9. T.L.Teel, M.J. Manfredo. Understanding the diversity of public interests in wildlife conservation. Conservation Biology, 24(1), 128-139 (2010).

10. B. J. Bergstrom, L. C. Arias, A. D. Davidson, A. W. Ferguson, L. A. Randa, \& S. R. Sheffield. Conservation Letters, 7(2), 131-142 (2014). http://onlinelibrary.wiley.com/doi/10.1111/conl.12045/full

11. S. D. Dubois (2014). Understanding humane expectations: public and expert attitudes towards human-wildlife interactions. Unpublished Phd dissertation retrieved on 13/5/2016 from: https://open.library.ubc.ca/cIRcle/collections/ubctheses/24/items/1.0165855

12. Ipsos MORI. Openness in Animal Research - the public's views on openness and transparency in animal research. Ipsos MORI, 2013. Retrieved on 20 May, 2016 from : http://www.understandinganimalresearch.org.uk/policy/concordatopenness-animalresearch/openness-in-animalresearch-public-dialogue/

13. A.Treves, R.B. Wallace, L.Naughton-Treves, A. Morales. Human Dimensions of Wildlife, 11(6), 383-396 (2006)

14. S.L.Hanisch-Kirkbride, J.P.Burroughs,S.J. Riley. Human Dimensions of Wildlife, 19(3), 253-266 (2014)

15. M. J. Manfredo, T.L. Teel, K.L. Henry. Social Science Quarterly, 90(2), 407-427 (2009)

16. Western Research Institute (WRI). 2012 Supercheap Auto Bathurst 1000. Economic Impact Report. Retrieved on 22 April 2016 from http://www.wri.org.au/images/docs/annual_reports/Final_2012_Supercheap_Auto_Bat hurst_1000_Economic_Impact_Report.pdf 
17. Bathurst Regional Council (BRC). Mount Panorama Fauna. Bathurst Regional Council report and proposal to cull kangaroos. Dated 9 December 2015. Copy held by the author and available on request.

18. B. Cubby. Kangaroos are the big losers in this year's Bathurst 1000. Sydney Morning Herald newspaper, 2 October, 2009. Retrieved on 23 April 2016 from http://www.smh.com.au/environment/kangaroos-are-the-big-losers-in-this-yearsbathurst-1000-20091001-ger3.html

19. T. Carpenter. Bathurst Kangaroo Cull: Cr Tracey Carpenter. Youtube video. Retrieved on 23 April 2016 from https://www.youtube.com/watch? $\mathrm{v}=\mathrm{BwCaX8jXtI0}$

20. F. Molloy. Finding kinder ways to live with Australia's wildlife. $B B C$ News, 5 November 2014. Retrieved on 21 April, 2016 from http://www.bbc.com/news/worldaustralia-29644228

21. Bathurst Kangaroo Project (BKP) Facebook page. Retrieved on 23 April, 2016 from https://www.facebook.com/bathurstkangarooproject/

22. L. Eddy. The Western Advocate newspaper, 30 March 2016. Bathurst Regional Council's secret plan for a cull on the Mount. Retrieved online on 23 April, 2016 from http://www.westernadvocate.com.au/story/3818137/roos-in-the-headlights/

23. N. Morton The Western Advocate newspaper, 31 March 2016. Ecologist's simple solution to save Mount Panorama roos. Retrieved on 21 April, 2016 from http://www.westernadvocate.com.au/story/3821474/ecologists-simple-solution-tosave-mount-panorama-roos/?cs $=115$

24. G. Coote. Mount Panorama cull plans to be put on hold: council. ABC News website. Retrieved on 23 April 2016 from http://mobile.abc.net.au/news/2016-03-30/concernabout-proposed-kangaroo-cull-at-bathurst/7284296

25. J.W. Yeates, B. Reed. Animal research through a lens: transparency on animal research. Journal of Medical Ethics, 41(7), 504-5 (2015). 